\begin{tabular}{|c|l|}
\hline Title & Preparation of electrode for electric double layer capacitor from electrospun lignin fibers \\
\hline Author(s) & You, Xiangyu; Koda, Keiichi; Y amada, Tatsuhiko; U raki, Y asumitsu \\
\hline Citation & $\begin{array}{l}\text { Holzforschung, 69(9), 1097-1106 } \\
\text { https://loi.org/10.1515/hf-2014-0262 }\end{array}$ \\
\hline Issue Date & $2015-11$ \\
\hline Doc URL & http://hdl.handle.net/2115/63389 \\
\hline Type & article \\
\hline File Information & $71527($ uraki)pdf.pdf \\
\hline
\end{tabular}

Instructions for use 
Xiangyu You, Keiichi Koda, Tatsuhiko Yamada and Yasumitsu Uraki*

\section{Preparation of electrode for electric double layer capacitor from electrospun lignin fibers}

\begin{abstract}
Lignin-based activated carbon fibers (ACFs) were prepared by electrospinning of hardwood acetic acid lignin (HW-AAL) solution followed by thermostabilization, carbonization, and steam activation. The thermostabilization process was able to be remarkably shortened from $38 \mathrm{~h}$ to $3 \mathrm{~h}$ with hexamethylenetetramine (hexamine) in binary solvents, $\mathrm{AcOH} / \mathrm{CCl}_{4}$ (8/2), when compared with conventional thermostabilization processes. The resultant ACFs possessed higher specific surface area $\left(2185 \mathrm{~m}^{2} \mathrm{~g}^{-1}\right)$ than those from commercial activated carbon and electrospun lignin fibers without hexamine. These ACFs also exhibited good electrical capacitance $\left(133.3 \mathrm{~F} \mathrm{~g}^{-1}\right.$ at a current density of $1 \mathrm{~A} \mathrm{~g}^{-1}$ ) as electrodes of electric double layer capacitor (EDLC) are efficient not only due to their large surfaces area but also due to their porous structure with well-developed micropores (diameter: 0.5-1.3 nm). High energy density and power density of this EDLC ( $42 \mathrm{Wh} \mathrm{kg}^{-1}$ and $91 \mathrm{~kW} \mathrm{~kg}^{-1}$ respectively) were also achieved.
\end{abstract}

Keywords: electric double layer capacitor, electrospinning, lignin-based activated carbon fibers, pore size distribution, surface area

DOI 10.1515/hf-2014-0262

Received September 26, 2014; accepted January 16, 2015; previously published online February 19, 2015

\section{Introduction}

Innovative technologies with bio-based products can reduce the dependence on fossil resources (Bozell and

\footnotetext{
*Corresponding author: Yasumitsu Uraki, Research Faculty of Agriculture, Hokkaido University, Sapporo 060-8589, Japan, Phone: +81 011706 2817, Fax: +81 011706 2817,

e-mail: uraki@for.agr.hokudai.ac.jp. http://orcid.org/0000-0001-9931-922X

Xiangyu You: Graduate School of Agriculture, Hokkaido University, Sapporo 060-8589, Japan

Keiichi Koda: Research Faculty of Agriculture, Hokkaido University, Sapporo 060-8589, Japan

Tatsuhiko Yamada: Forestry and Forest Products Research Institute, Division of Biomass Chemistry, Tsukuba 305-8687, Japan
}

Petersen 2010). Cellulose and lignin are the most and second abundant components of plant biomass, respectively. Lignin as a by-product of pulp and paper industry is mainly burned for energy recovery (Calvo-Flores and Dobado 2010). For sustainable production processes based on renewable resources, lignin utilization is one of the key not only for energetic purposes but also as a source of chemicals and plastics. Lignin is promising for development of carbonaceous value-added functional materials such as activated carbons (Suhas et al. 2007), carbon fibers (CFs) (Kadla et al. 2002; Kubo and Kadla 2005) and activated carbon fibers (ACFs) (Babel and Jurewicz 2008; Rosas et al. 2009). ACFs contain micropores, which are directly exposed to the surface of the fiber, while in activated carbons, macropores and mesopores are formed within the cell wall. Fast adsorption/desorption of adsorbate molecules is typical for ACFs (Inagaki 2009). ACFs could be prepared from hardwood and softwood acetic acid lignins (HW-AAL and SW-AAL, respectively) by melt spinning followed by thermostabilization, carbonization, and steam activation after pretreatments (Uraki et al. 2001), which have a high potential as adsorbents.

Recently, ACFs were tested as electrode material for electric double layer capacitor (EDLC) (Liu et al. 2007; Xu et al.2007). EDLC is an energy storage device, and could be an alternative to secondary battery like lithium ion battery (Simon and Gogotsi 2008) because of its advantages: high power density, short charging time, long cycle life, and environmental friendliness (Bose et al. 2012; Wang et al. 2012). However, the disadvantage of EDLC is its low energy density with $4-5 \mathrm{Wh} \mathrm{kg}^{-1}$, which is approximately $1 / 10$ the energy density of the secondary batteries (Burke 2007). EDLC stores electric energy in an electric double layer formed by physical sorption of electrolyte ions onto carbonaceous electrode. Accordingly, one possible method to improve energy density is to develop electrode materials with higher capacitance, which will be achieved by the preparation of carbon materials with larger surface area and suitable pore size for accumulation and transportation of more electrolytes (Inagaki et al. 2010). In addition, organic electrolytes may also enhance energy density because its potential window $(0-3 \mathrm{~V})$ is wider than those of aqueous electrolytes (0-1 V) (Zhang and Zhao 2009; ElKady et al. 2012). 
There are a few reports on EDLC preparation from lignin-based carbonaceous electrode (Lai et al. 2014; Ruiz-Rosas et al. 2014). The EDLC with a remarkably high capacitance of $202 \mathrm{~F} \mathrm{~g}^{-1}$, measured at a current density of $0.05 \mathrm{~A} \mathrm{~g} \mathrm{~g}^{-1}$, could be fabricated with aqueous electrolyte, but the energy density (less than $6 \mathrm{Wh} \mathrm{kg}^{-1}$ ) is low due to the limited window potential.

Therefore, an objective of the present study is to prepare EDLC electrode with a large capacitance and a high energy density from HW-AAL. The following strategy was followed to obtain carbonaceous material with large surface area: electrospun fibers of HW-AAL (Feng and Aorigele 2009) should be the source for ACFs. However, it requires a long time to thermostabilize the fibers as a process step of ACFs preparation. Thereby, novel electrospun fibers should be developed from a mixture of HW-AAL and hexamethylenetetramine (hexamine), which can be easily converted to thermostabilized fibers within 3 h. Furthermore, EDLC should be assembled with the resultant ACFs and organic electrolyte, triethylmethylammonium tetrafluoroborate $\left(\mathrm{TEMABF}_{4}\right) /$ propylene carbonate $(\mathrm{PC})$. This article reports the preparation process and electrochemical properties of the EDLC.

\section{Materials and methods}

The flow diagram of ACF preparation and EDLC assembly is shown in Figure 1. HW-AAL was isolated from birch wood chips (white birch, Betula platyphylla Sukachev var. japonica Hara) by atmospheric acetic acid pulping (Uraki et al. 1995). HW-AAL was dissolved in AcOH or binary solvents of $\mathrm{AcOH} / \mathrm{CCl}_{4}$ (weight ratio, 8:2), and then a different amount of hexamine was added to the solution. The mixture was

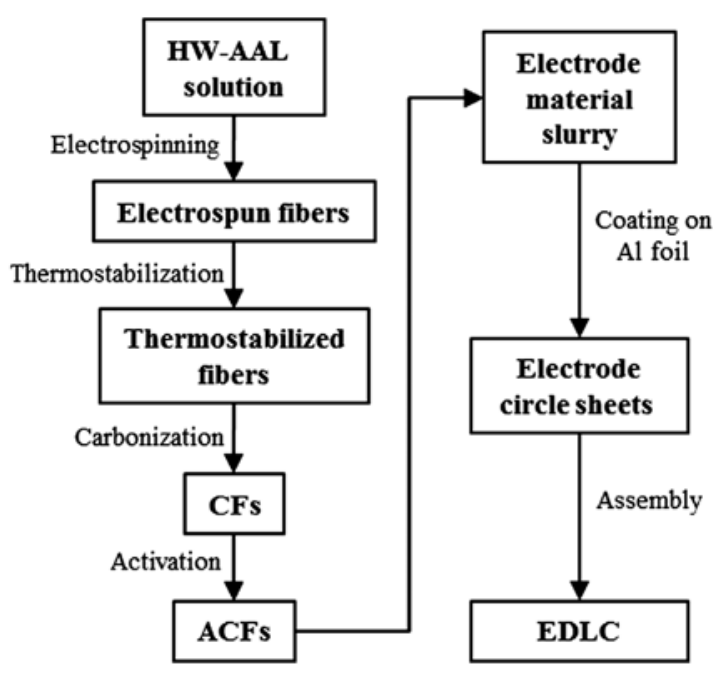

Figure 1: Flow diagram of ACFs preparation and EDLC assembly. stirred at $80^{\circ} \mathrm{C}$ for $2 \mathrm{~h}$. The mixture solution was subjected to electrospinning under the following conditions: voltage $38 \mathrm{kV}$; solution flow rate, $0.2 \mathrm{ml} \mathrm{min}^{-1}$; tip-collector distance, $13 \mathrm{~cm}$. The electrospun lignin fibers were thermostabilized under air atmosphere by heating up to the final temperature of $250^{\circ} \mathrm{C}$ at a heating rate of $2^{\circ} \mathrm{C} \mathrm{min}^{-1}$, and the temperature was held for $1 \mathrm{~h}$. The thermostabilized fibers were carbonized under $\mathrm{N}_{2}$ stream at $1000^{\circ} \mathrm{C}$ for $1 \mathrm{~h}\left(3^{\circ} \mathrm{C} \mathrm{min}{ }^{-1}\right)$. The resultant CFs were activated at $900^{\circ} \mathrm{C}$ with steam, which was introduced into an electric furnace by $\mathrm{N}_{2}$ gas (flow rate $0.51 \mathrm{~min}^{-1}$ ) after heating up to the temperature at a heating rate of $10^{\circ} \mathrm{C} \mathrm{min}-1$ under $\mathrm{N}_{2}$ stream. The resultant lignin-based $\mathrm{CFs}$ and $\mathrm{ACF}$ derived from the binary solvent system $\left(\mathrm{AcOH} / \mathrm{CCl}_{4}\right)$ are named as LCF-2 and LACF-2, respectively, to be distinguished from LCF-1 and LACF-1, which were derived from single solvent (AcOH). Specifically, a volume of introduced water in milliliter is designated at the end of ACF samples (e.g., LACF-2-105 stands for $105 \mathrm{ml} \mathrm{H}_{2} \mathrm{O}$ consumption in the activation process).

$M_{w}$ and polydispersity of the HW-AAL were determined by SEC (Class VP for GPC, Shimadzu, Kyoto, Japan) equipped with a column of Shodex KF-803L at $40^{\circ} \mathrm{C}$. THF was used as the eluent $\left(0.5 \mathrm{ml} \mathrm{min}^{-1}\right)$, and the UV detection was at $280 \mathrm{~nm}$. The HW-AAL concentration in THF was $5 \mathrm{mg} \mathrm{ml}^{-1}$, and the injection volume was $20 \mu \mathrm{l}$. The columns were calibrated by polystyrene standards.

Fiber morphology was observed under an optical microscope (Violet laser color 3D profile microscope VK-9500, Keyence Japan, Osaka, Japan) or with a SEM instrument (JSM-6301F, JOEL Ltd., Tokyo, Japan) at an accelerating voltage of $5 \mathrm{kV}$ after gold sputtering.

$\mathrm{N}_{2}$ adsorption/desorption isotherms at $-196^{\circ} \mathrm{C}$ was monitored on a surface area analyzer (Autosorb-1, Quantachrome, Tokyo, Japan). The specific surface area was calculated from $\mathrm{N}_{2}$ adsorption isotherms in the range of the relative pressure $\left(P / P_{0}\right)$ from 0.02 to 0.30 according to the Brunauer-Emmett-Teller (BET) model (Fitzer and Müller 1975). The internal and external surface areas were ascertained according to $t$-plot method in the relative pressure range of 0.2 0.5 (Wang et al. 2012). In addition, the average pore size, accompanied with cumulative surface area and pore size distribution in the pore range of 0.6 to $5.0 \mathrm{~nm}$, was calculated from adsorption isotherm based on quenched solid density functional theory (QSDFT) (Neimark et al. 2009).

EDLC of symmetric two-electrode cell was assembled with the LACF-2 or commercially available activated carbon powder (AC powder, Wako Pure Chemical Industries, Co., Ltd., Tokyo, Japan) as a reference material, sodium carboxymethyl cellulose (CMC) as a binder, and conductive carbon black (CB, Super P conductive, 99+\%, Alfa Aesar, Heysham, England), at the weight ratio of 85:10:5. Each sample together with CB was added to $2 \%$ of aqueous CMC solution, and then the mixture was ultrasonicated by an ultrasonic washer (5510RDTH, Branson Ultrasonics, Emerson Japan Ltd., Tokyo, Japan) for $2 \mathrm{~h}$ to give homogeneous slurry. Subsequently, the mixture was coated on $\mathrm{Al}$ foil, and the $\mathrm{Al}$ foil was dried at $105^{\circ} \mathrm{C}$ overnight. The coated $\mathrm{Al}$ foil was cut into a circle with a diameter of $16 \mathrm{~mm}$ (circle sheets), and the sheets were kept in an oven at $105^{\circ} \mathrm{C}$ before the assembling process. The solid weight on the $\mathrm{Al}$ foil was calculated by the difference between the weights before and after deposition of specimens, and two sheets with less than $0.1 \mathrm{mg}$ of weight difference were used in a pair for EDLC assembly. Herein, $1 \mathrm{M} \mathrm{TEMABF} / \mathrm{PC}$ served as electrolyte; cellulosic paper (Mitsubishi paper Mills Ltd. Tokyo, Japan) was used as separator.

The electrochemical properties were evaluated by means of an electrochemical workstation (Autolab PGSTAT302N FRA32M, Metrohm Autolab B.V., Tokyo, Japan). Cyclic voltammetry (CV) was monitored with a potential window from 0 to $3 \mathrm{~V}$ at different scan rates 
from 0.01 to $0.1 \mathrm{~V} \mathrm{~s}^{-1}$, and specific capacitance was calculated from cyclic voltammogram according to Equation (1) (Qu and Shi 1998). Herein, we used an instantaneous value, $C_{1.5}$ (approximate value of real specific capacitance) at intermediate value in the potential range:

$$
C_{1.5}=\frac{4 I}{m \cdot V / t}
$$

where $I$ is the current formed at the potential of $1.5 \mathrm{~V}, \mathrm{~V} / \mathrm{t}$ is the potential scanning rate, and $m$ refers to the total weight of the materials on two electrodes. Galvanostatic charge/discharge (GCD) measurements were carried out at a current density of $1 \mathrm{~A} \mathrm{~g}^{-1}$ within the voltage range of $0-3 \mathrm{~V}$. The specific capacitance, $C$, for a single electrode was calculated from the GCD curves by Equation (2) (Qu and Shi 1998):

$$
C=\frac{4 i}{m \cdot d V / d t}
$$

where $i$ is the applied current, CMC and CB, and $d V / d t$ is the slope obtained by fitting a straight line to the discharge curve over the range from $1.8 \mathrm{~V}$ to $1.35 \mathrm{~V}\left(60-45 \%\right.$ of $V_{\max }$, where $V_{\max }$ is the maximum value of the operating potential window). The energy density, $E$, was estimated by using Equation (3) (Kim et al. 2013):

$$
E=\frac{1}{8} C V_{\max }^{2}
$$

The power density, $P$, was estimated at certain constant current $i$, according to Equation (4) (Kim et al. 2013):

$$
P=\frac{i\left(V_{\max }-V_{\text {drop }}\right)^{2}}{2 m V_{\text {drop }}}
$$

where $V_{\text {drop }}$ is the voltage drop at the beginning of the discharge. Electrochemical impedance spectroscopy (EIS) experiments were carried out at open circuit potential with a sinusoidal signal with amplitude of $10 \mathrm{mV}$ over a frequency range of $100 \mathrm{kHz}-1 \mathrm{~Hz}$.

\section{Results and discussion}

\section{Electrospinning of HW-AAL and thermostabilization of the fibers}

HW-AAL with the weight average molecular weight $\left(M_{w}\right)$ of 7851 and the polydispersity $\left(M_{w} / M_{n}\right)$ of 4.6 was dissolved in $\mathrm{AcOH}$ to prepare a homogeneous solution as a dope at a concentration range of $30-40 \%$. Figure 2 clearly shows that electrospun fibers were obtained from the solution at $35 \%$ and $40 \%$ concentrations at an applied voltage of 38 $\mathrm{kV}$; thus, a relatively high concentration was required for the spinning. Diameters of the HW-AAL fibers from 35\% and $40 \%$ solutions were 1.30 and $1.51 \mu \mathrm{m}$, respectively (Table 1). Therefore, the solution with a higher concentration gave thicker fibers.

Because of the thermal fusibility of HW-AAL and its fibers, the electrospun fibers were subjected to the thermostabilization as a second process for preparation of
CFs, which generated infusible fibers. In general, it was performed by heating the fibers gradually to about $250^{\circ} \mathrm{C}$ in an air atmosphere (Kubo et al. 1998). Unfortunately, the HW-AAL fibers were melted during the heating even at relatively slow heating rate of 0.3 and $0.5^{\circ} \mathrm{C} \mathrm{min}^{-1}$. The product morphologies are also shown in Figure 2. The thermostabilized fibers could possibly be obtained only at the heating rate of $0.1^{\circ} \mathrm{C} \mathrm{min}{ }^{-1}$, which would have needed a 38 -h treatment time, which is not acceptable in an industrial process. Accordingly, these HW-AAL fibers were not suitable as a precursor of CFs. However, such a very slow thermostabilization process would lead to fine thermostabilized fibers with an average diameter of $0.87 \mu \mathrm{m}$ (Figure $2 \mathrm{~d}$ ).

Thermostabilization of precursory fibers for CFs was carried out by crosslinking, and this process has to be accelerated by the introduction of a crosslinker into the lignin molecules. Hexamine was attempted for this purpose as it is decomposing to formaldehyde, which is a crosslinker for phenol-formaldehyde resin and ammonia under acidic conditions (Martin et al. 2006). When hexamine was mixed with HW-AAL/AcOH solution, the resultant solution was not suited to electrospinning because of the high viscosity of the solution.

Hence, HW-AAL and hexamine were dissolved in the binary solvent $\mathrm{AcOH} / \mathrm{CCl}_{4}$ and suppressed the viscosity increment because the viscosity of $\mathrm{CCl}_{4}\left(0.97 \mathrm{mPa} \cdot \mathrm{s}, 20^{\circ} \mathrm{C}\right)$ is smaller than that of $\mathrm{AcOH}\left(1.21 \mathrm{mPa} \cdot \mathrm{s}, 20^{\circ} \mathrm{C}\right)$, and the acidity of the solution was weaker than with $\mathrm{AcOH}$ alone. Expectedly, HW-AAL could be successfully electrospun from such a mixture solution at a concentration of $35 \%$ as shown in Figure 3. Table 1 summarizes the spinning conditions and the average diameter of the obtained fibers, where missing values in average diameter shows unsuccessful electrospinning. The average diameter of electrospun fibers were increased with increasing hexamine concentration. These results indicate that a larger amount of hexamine contributes to bigger molecular bundles.

Spun fabrics (fiber mat) containing 7.5\% and 10\% of hexamine could be easily thermostabilized by heating in air up to $250^{\circ} \mathrm{C}$ at a heating rate of $2^{\circ} \mathrm{C} \mathrm{min}$ m $^{-1}$ followed by stabilization at this temperature for $1 \mathrm{~h}$. However, the fabrics with $5 \%$ hexamine were partly melted during this process. Thus, thermostabilization time was remarkably shortened from $38 \mathrm{~h}$ to less than $3 \mathrm{~h}$ by the addition of hexamine. The average diameter of fibers was also decreased by this thermostabilization from 3.8 to $3.7 \mu \mathrm{m}$ for the fibers with $7.5 \%$ hexamine, from 5.2 to $3.5 \mu \mathrm{m}$ for those with $10 \%$ hexamine as shown in Tables 1 and 2 . The rate of diameter decrement with $7.5 \%$ hexamine was lower, which is surprising but might be explained by the following hypothesis. The lignin fibers can be divided into completely 

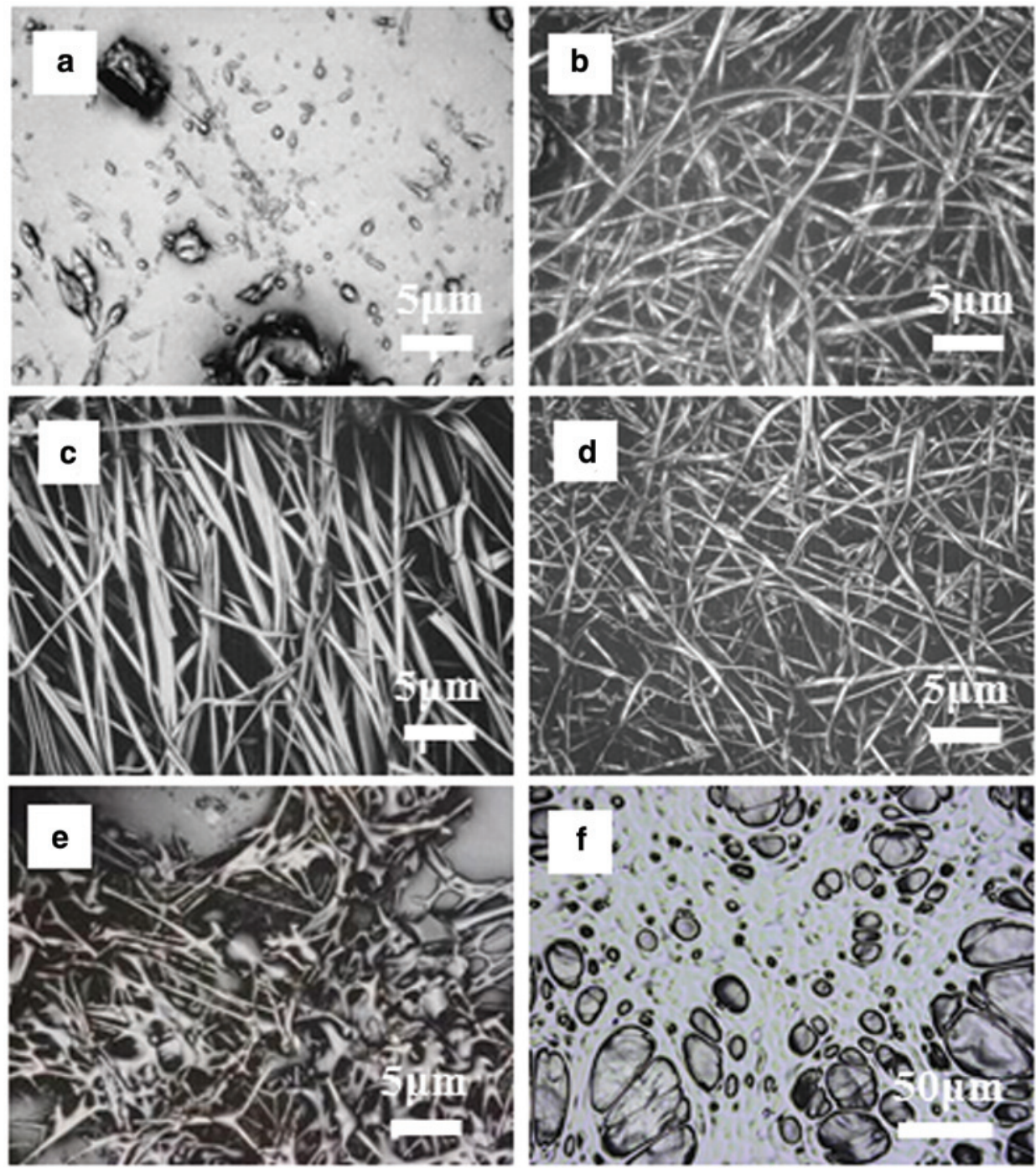

Figure 2: Microscopic images of electrospinning products at different concentrations of HAL/AcOH solution, (a) $30 \mathrm{wt} \%$; (b) $35 \mathrm{wt} \%$; (c) 40 wt $\%$, and thermostabilization products at different heating rates, (d) $0.1^{\circ} \mathrm{C} \mathrm{min}^{-1}$; (e), $0.3^{\circ} \mathrm{C} \mathrm{min}^{-1}$; (f), $0.5^{\circ} \mathrm{C} \mathrm{min}^{-1}$ (precusor, electrospun fiber derived from $35 \mathrm{wt} \% \mathrm{HAL} / \mathrm{AcOH}$ solution).

Table 1: Electrospinning conditions and average diameter of electrospun fibers.

\begin{tabular}{lrrr}
\hline Solution & $\begin{array}{r}\text { Solution } \\
\text { conc. (\%) }\end{array}$ & $\begin{array}{r}\text { Hexamine } \\
\text { content (\%) }\end{array}$ & $\begin{array}{r}\text { Avg. diameter } \\
(\mu \mathrm{m})\end{array}$ \\
\hline $\mathrm{HW}-\mathrm{AAL} / \mathrm{AcOH}$ & 30 & 0 & - \\
$\mathrm{HW}-\mathrm{AAL} / \mathrm{AcOH}$ & 35 & 0 & $1.30 \pm 0.20$ \\
$\mathrm{HW}-\mathrm{AAL} / \mathrm{AcOH}$ & 40 & 0 & $1.51 \pm 0.24$ \\
$\mathrm{HW}-\mathrm{AAL} / \mathrm{AcOH}$ & 35 & 10 & - \\
$\mathrm{HW}-\mathrm{AAL} / \mathrm{ACOH} / \mathrm{CCl}_{4}$ & 35 & 5 & $1.51 \pm 2.34$ \\
$\mathrm{HW}-\mathrm{AAL} / \mathrm{ACOH} / \mathrm{CCl}_{4}$ & 35 & 7.5 & $3.80 \pm 1.63$ \\
$\mathrm{HW}-\mathrm{AAL} / \mathrm{ACOH} / \mathrm{CCl}_{4}$ & 35 & 10 & $5.17 \pm 2.33$ \\
\hline
\end{tabular}

crosslinked and thermally stable inside part and poorly crosslinked thermally unstable outside part, which is due to the higher surface area as the reaction sites are increasing exponentially at the surface area. The hexamine concentration is lower in the outer part than that in the inner part. The fiber has a kind of core-shell structure. If the shell of fibers with $10 \%$ hexamine is thicker than that with $7.5 \%$ hexamine, with both fibers having almost the same diameter of the core, then it is possible that fibers with $10 \%$ hexamine seemingly shrinks more than those with $7.5 \%$ hexamine.

\section{Carbonization and activation of thermostabilized HW-AAL fibers}

The thermostabilized HW-AAL electrospun fibers with hexamine were converted to CFs by carbonization at 

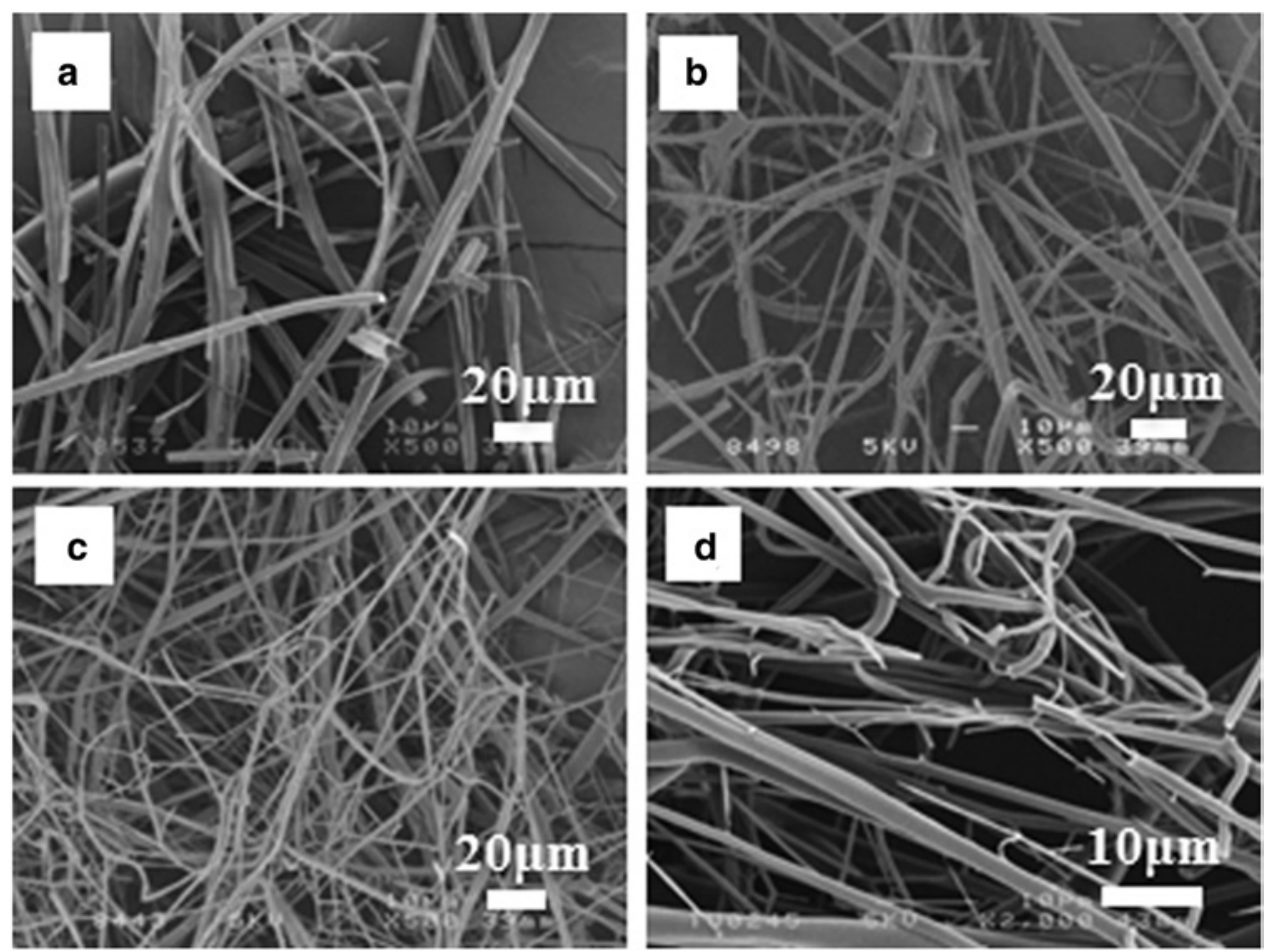

Figure 3: SEM images of lignin-based fibrous products at $10 \mathrm{wt} \%$ of hexamine content, (a) electrospun fibers; (b) thermostabilized fibers; (c) LCF-2; and (d) LACF-2-105.

Table 2: Diameter of the resultant fibers after heat treatment at $250^{\circ} \mathrm{C}$ (heating rate of $2^{\circ} \mathrm{C} \mathrm{min}^{-1}$ ) for $1 \mathrm{~h}$.

\begin{tabular}{lrr}
\hline Samples & $\begin{array}{r}\text { Hexamine } \\
\text { content }(\%)\end{array}$ & $\begin{array}{r}\text { Avg. diameter } \\
(\mu \mathrm{m})\end{array}$ \\
\hline Thermostab. fibers & 7.5 & $3.72 \pm 2.58$ \\
Thermostab. fibers & 10 & $3.49 \pm 2.17$ \\
LCF-2 & 7.5 & $2.53 \pm 1.89$ \\
LCF-2 & 10 & $1.73 \pm 1.00$ \\
LACF-2-105 & 10 & $1.42 \pm 0.94$ \\
LACF-2-180 & 10 & $1.34 \pm 1.03$ \\
\hline
\end{tabular}

$1000^{\circ} \mathrm{C}$ for $1 \mathrm{~h}$ under a $\mathrm{N}_{2}$ stream (Figure 3). The average diameters of the resultant CFs at $7.5 \%$ and $10 \%$ of hexamine content were $2.5 \mu \mathrm{m}$ and $1.7 \mu \mathrm{m}$, respectively, i.e., thinner CFs were obtained at $10 \%$ of hexamine. Interestingly, the surface of CFs (LCF-1) derived from HW-AAL/ $\mathrm{AcOH}$ solution was very smooth, while the CFs obtained from the binary solvents $\left(\mathrm{AcOH} / \mathrm{CCl}_{4}\right)$ exhibited a large amount of cracks and pores (Figure 4). The mechanism of pore generation is assumed to be as follows: $\mathrm{AcOH}$ is a good solvent with strong interaction for HW-AAL. As a result, unsolvated $\mathrm{CCl}_{4}$ is easily evaporated from spinning dope to generate the pores during the coagulation process of electrospinning, and the porous morphology of the fibers are maintained even after the subsequent heat treatment including carbonization and steam activation.

The LCF-2 prepared with $10 \%$ of hexamine were, in turn, activated with steam at $900^{\circ} \mathrm{C}$ for $1 \mathrm{~h}$ to prepare LACF-2. The average diameter of LACF-2-105 was $1.4 \mu \mathrm{m}$, which was significantly decreased by the carbonization and activation. Additionally, LACF-2-180 (SEM images not shown here) was also prepared, and it exhibited the similar morphology with an average diameter of $1.3 \mu \mathrm{m}$.

\section{Surface area and pores of CFs and ACFs}

Specific surface area of HW-AAL-based CFs and ACFs were calculated from $\mathrm{N}_{2}$ adsorption isotherms by the BET method, and their pore size distribution were measured from $\mathrm{N}_{2}$ adsorption by QSDFT. Results are listed in Table 3. The specific BET surface area (expressed at standard temperature and pressure) of LCF-1 was $532 \mathrm{~m}^{2} \mathrm{~g}^{-1}$, while that of LCF-2 was $1287 \mathrm{~m}^{2} \mathrm{~g}^{-1}$. The larger surface area of LCF-2 can be attributed to porous morphology of electrospun fibers from the mixture. The surface area of LCF-2 was almost comparable to that of commercial AC powder $\left(1434 \mathrm{~m}^{2} \mathrm{~g}^{-1}\right)$ in spite of not being activated. Furthermore, this value was larger than CFs derived from electrospun fibers of synthetic polymers previously reported [PAN, 11.4-340.9 $\mathrm{m}^{2} \mathrm{~g}^{-1}$ 


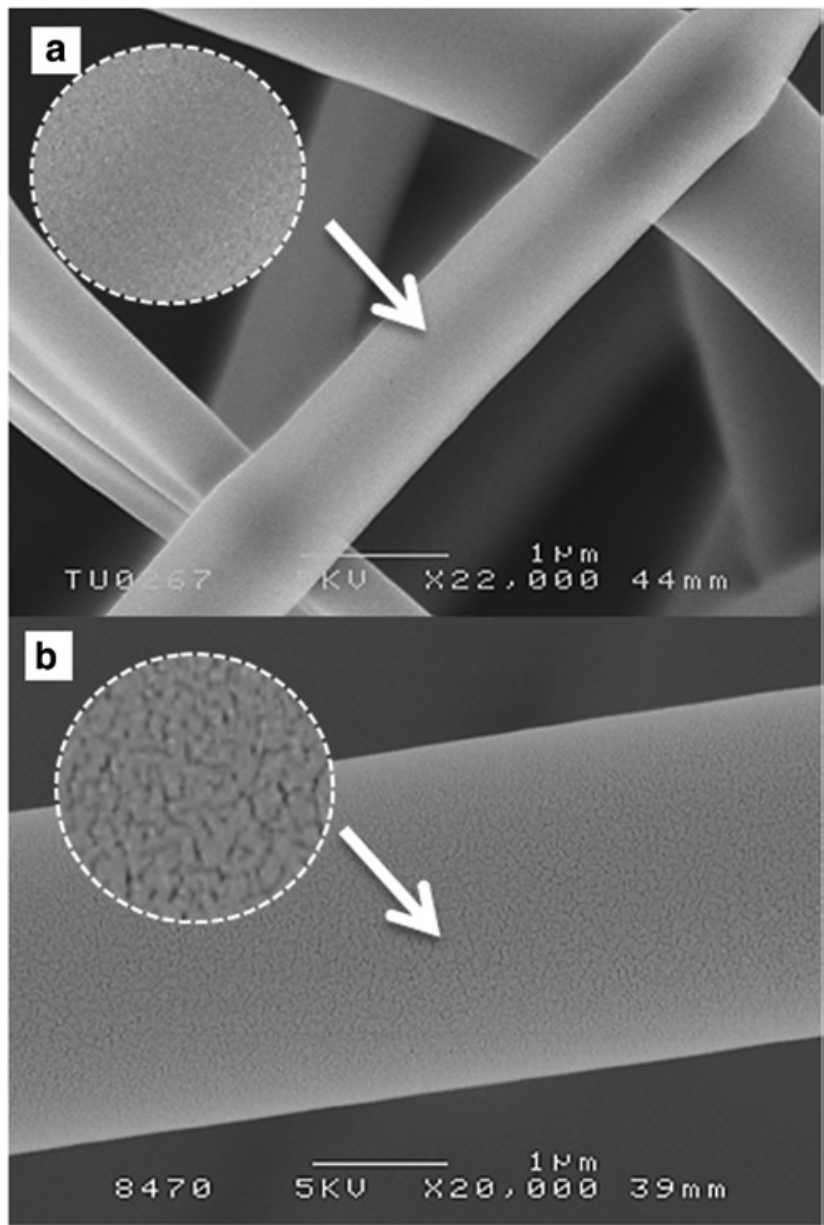

Figure 4: Magnified SEM images of ACFs prepared from (a) a single solvent system (LACF-1-105) and (b) a binary solvent system (LACF-2-105).

(Im et al. 2007); phenolic resin, $792.7 \mathrm{~m}^{2} \mathrm{~g}^{-1}$ (Imaizumi et al. 2009); polyvinylalcohol/phenol formaldehyde, $564 \mathrm{~m}^{2} \mathrm{~g}^{-1}$ (Liu et al. 2012)].
Similarly, steam-activated LCF-2 (LACF-2-105 and LACF-2-180) also have much larger surface area (2185 and $2447 \mathrm{~m}^{2} \mathrm{~g}^{-1}$, respectively) than the activated LCF-1 (LACF$\left.1-105,979 \mathrm{~m}^{2} \mathrm{~g}^{-1}\right)$. Both values of LACF-2 are higher than that of ACF derived from electrospun fibers of PAN (850$1230 \mathrm{~m}^{2} \mathrm{~g}^{-1}$ ) (Kim and Yang 2003). From $t$-plot, the internal surface area, as an adsorption site, of both LACF-2, was much larger than that of commercial AC powder, suggesting that LACF-2 mainly consists of micro- and mesopores. Figure 5a obtained by the calculation based on the QSDFT method clearly shows that LACF- 2 is comprised of pores in the diameter range from $0.5 \mathrm{~nm}$ to $3.0 \mathrm{~nm}$, which are well developed, compared with that of LACF-1 $(0.5 \mathrm{~nm}$ to $1.2 \mathrm{~nm}$ ). Specifically, the pore size distribution of LACF-2105 is rich in the range of $0.5-1.4 \mathrm{~nm}$, while that of LACF-2180 is converted to a larger region of $1.4-3.0 \mathrm{~nm}$ as shown in Figure $5 \mathrm{~b}$. On the other hand, the AC powder had a large pore volume of $1.39 \mathrm{ml} \mathrm{g}^{-1}$, but Figure 5 and the external surface area shows that most pores consist of macropores that are not involved in adsorption of guest molecules. This difference between LACF-2 and AC powder might affect the accumulation of the electrolyte ions, when EDLC is assembled with these materials. Thus, these results can be safely interpreted that electrospun fibers from a mixed solution of HW-AAL and hexamine in a binary solvent system contribute not only to the reduced time for thermostabilization but also to the increase in the surface area and pores amount of ACFs.

\section{EDLC assembly and its electrochemical properties}

EDLC was assembled with grinded LACF-2 or AC powder together with $\mathrm{CB}, \mathrm{CMC}$ as a binder, and with an organic

Table 3: Surface area and pore parameters of carbonaceous materials and the properties of assembled EDLC.

\begin{tabular}{|c|c|c|c|c|c|c|c|c|}
\hline Samples & $\begin{array}{r}\text { Activation } \\
\text { yield (\%) }\end{array}$ & $\begin{array}{r}\text { Specific } \\
\text { surface area } \\
\left(\mathrm{m}^{2} \mathrm{~g}^{-1}\right)^{\mathrm{a}}\end{array}$ & $\begin{array}{r}\text { Total pore } \\
\text { volume } \\
\left(\mathrm{ml} \mathrm{g}^{-1}\right)\end{array}$ & $\begin{array}{r}\text { Avg. pore } \\
\text { diam. } \\
(n m)^{b}\end{array}$ & $\begin{array}{r}\text { Internal } \\
\text { surface area } \\
\left(\mathrm{m}^{2} \mathrm{~g}^{-1}\right)^{\mathrm{c}}\end{array}$ & $\begin{array}{r}\text { External } \\
\text { surface area } \\
\left(\mathrm{m}^{2} \mathrm{~g}^{-1}\right)^{\mathrm{c}}\end{array}$ & $\begin{array}{r}\text { Specific } \\
\text { capacitance } \\
\left(\mathrm{F} \mathrm{g}^{-1}\right)^{\mathrm{d}}\end{array}$ & $\begin{array}{r}\text { Intrinsic } \\
\text { resistance } \\
(\Omega)\end{array}$ \\
\hline LCF-2 & - & 1287 & 0.62 & 0.93 & 1158 & 129 & - & - \\
\hline LACF-2-105 & 57.8 & 2185 & 1.15 & 0.93 & 1775 & 410 & 133.3 & 1.1 \\
\hline LACF-2-180 & 41.3 & 2447 & 1.58 & 1.80 & 1278 & 1169 & 63.5 & 1.1 \\
\hline LCF-1 & - & 532 & 0.28 & 0.93 & 432 & 100 & - & - \\
\hline LACF-1-105 & 61.5 & 979 & 0.46 & 1.00 & 861 & 118 & - & - \\
\hline AC powder & - & 1434 & 1.39 & 3.88 & 331 & 1103 & 65.2 & 2.4 \\
\hline
\end{tabular}

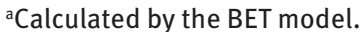

${ }^{\mathrm{b}}$ Calculated based on QSDFT model.

'Calculated according to $t$-plot method.

${ }^{\mathrm{d}}$ Calculated by GCD method. 

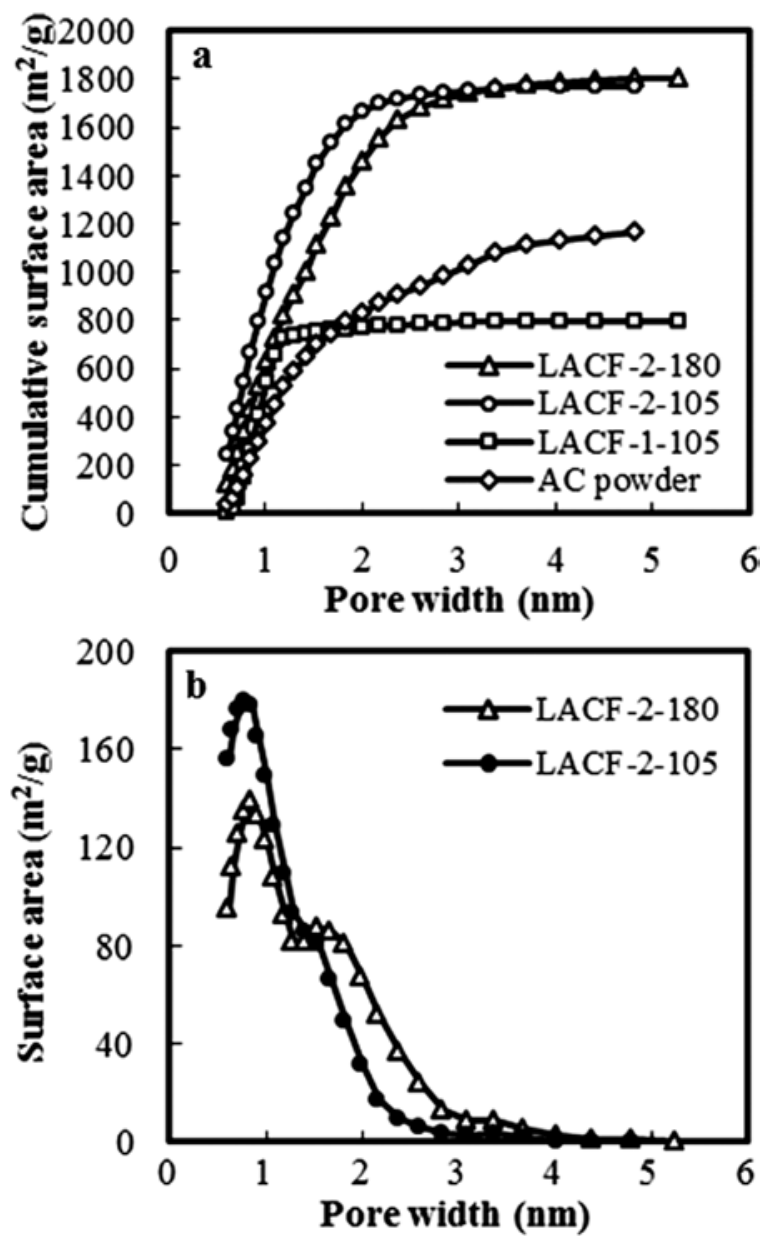

Figure 5: (a) Cumulative surface area and (b) surface area distribution of carbon materials in the pore range of $0.6-5.0 \mathrm{~nm}$ (calculated by using QSDFT model).

electrolyte $\mathrm{TEMABF}_{4} / \mathrm{PC}$. These constituents for EDLC were assembled in a two-electrode symmetrical cell. The electrochemical property of the resultant EDLCs were evaluated by CV, GCD, and EIS, as presented in Figures 6-8, respectively.

All CV profiles were monitored at a potential window from 0 to $3 \mathrm{~V}$ at different scan rates of $0.01,0.05$, and $0.1 \mathrm{~V} \mathrm{~s}^{-1}$. The cyclic voltammogram of EDLC $_{\mathrm{LACF}-2105}$ shows a nearly rectangular shape, and calculated capacitance values from $135 \mathrm{~F} \mathrm{~g} \mathrm{~g}^{-1}$ at the scan rate of $0.1 \mathrm{~V} \mathrm{~s}^{-1}$ to $143 \mathrm{~F} \mathrm{~g}^{-1}$ at the scan rate of $0.01 \mathrm{~V} \mathrm{~s}^{-1}$ are almost identical (Figure 6a). These results indicate that the EDLC has a good capacitive behavior and high-scan-rate stability. On the other hand, the $\mathrm{EDLC}_{\mathrm{ACpowder}}$ showed a lower value of $74.8 \mathrm{~F} \mathrm{~g}^{-1}$ at a scan rate of $0.05 \mathrm{~V} \mathrm{~s}^{-1}$ (Figure 6b). Even LACF-2-180 had a larger surface area than LACF-2-105, which might provide more adsorption sites for electrolyte ions, it only has a low capacitance of $69.2 \mathrm{~F} \mathrm{~g}^{-1}$. This huge difference is because LACF-2-105 has more abundant pores distributed in the
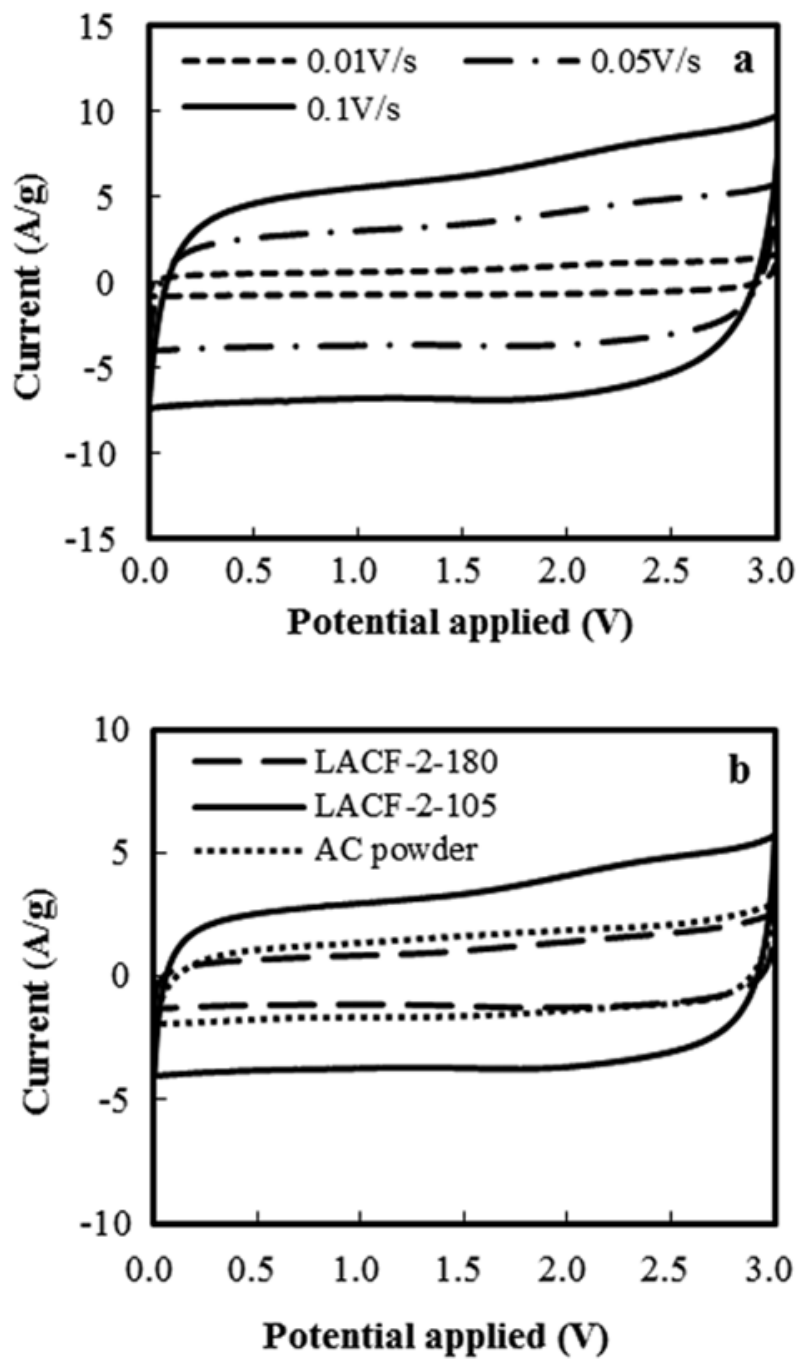

Figure 6: Cyclic voltammograms of LACF-2 and AC powder based EDLCs. (a) LACF-2-105 at different scan rates and (b) comparison of LACF-2-180, LACF-2-105, and AC powder at $0.05 \mathrm{~V} \mathrm{~s}^{-1}$.

range of $0.5-1.3 \mathrm{~nm}$ than LACF-2-180, which is in agreement with the finding that pores less than $1 \mathrm{~nm}$ lead an anomalous but significant increase in carbon capacitance (Chmiola et al.2006). Because the solvated electrolyte ions become highly distorted when they are squeezed through such small pores, and such distortion would allow closer approach of the ion center to the electrode surface, and this improves the capacitance.

From GCD measurement, the profile of $\mathrm{EDLC}_{\mathrm{LACF}-2105}$ and $\mathrm{EDLC}_{\mathrm{LACF}-2180}$ shows symmetrical triangles comprised of almost linear lines, and this triangle shape was repeatedly shown until 100 times even at a high current density of $1 \mathrm{~A} \mathrm{~g}^{-1}$ (Figure $7 \mathrm{a}$ and $\mathrm{b}$ ). These results also revealed the effective formation of electric double layer. The specific capacitance of LACF-2-105 from GCD was calculated as $133.3 \mathrm{~F} \mathrm{~g}^{-1}$ (Figure 7a), which was superior to $\operatorname{EDLC}_{\text {LACF-2180 }}\left(63.5 \mathrm{~F} \mathrm{~g}^{-1}\right)$ 

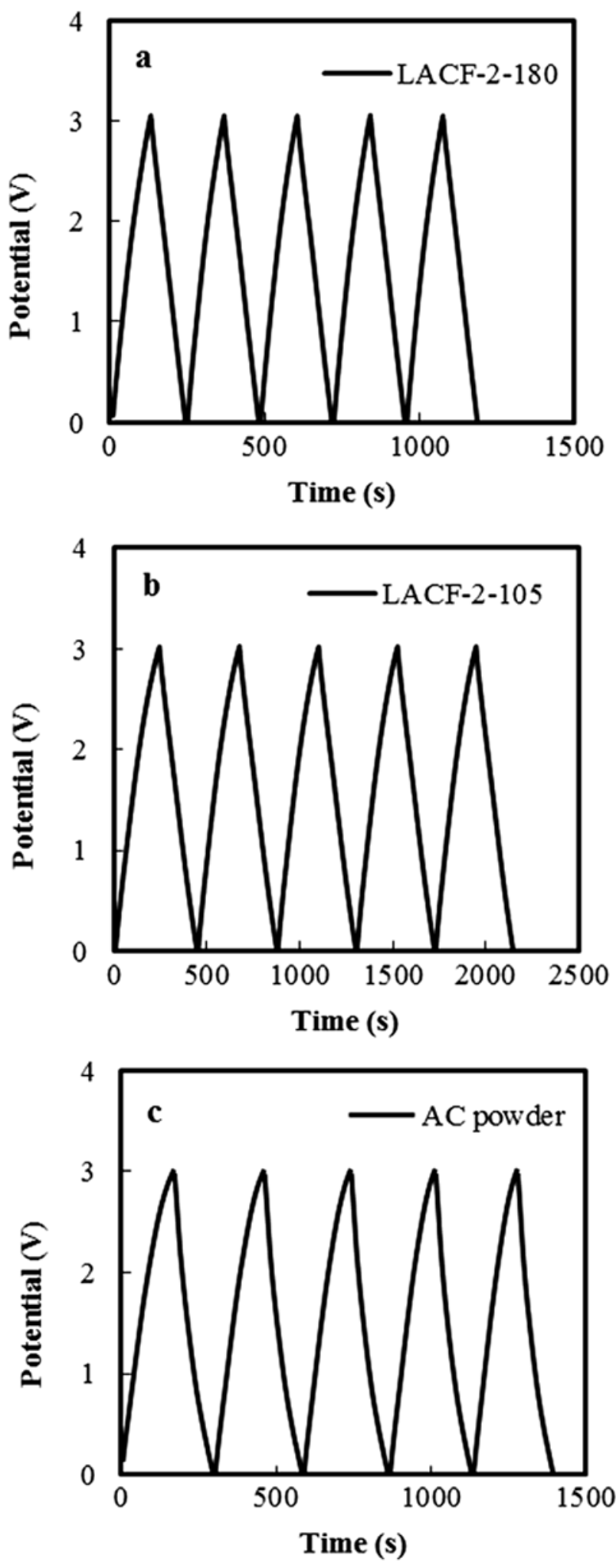

Figure 7: GCD profiles of (a) LACF-2-180, (b) LACF-2-105, and (c) AC powder-based EDLC under a current density of $1 \mathrm{~A} \mathrm{~g}^{-1}$.

(Figure $7 \mathrm{~b}$ ) and $\operatorname{EDLC}_{\text {ACpowder }}\left(65.2 \mathrm{~F} \mathrm{~g}^{-1}\right.$ ) (Figure 7c). It was also comparable to those assembled with different ACFs reported previously (Inagaki et al. 2010). Energy density
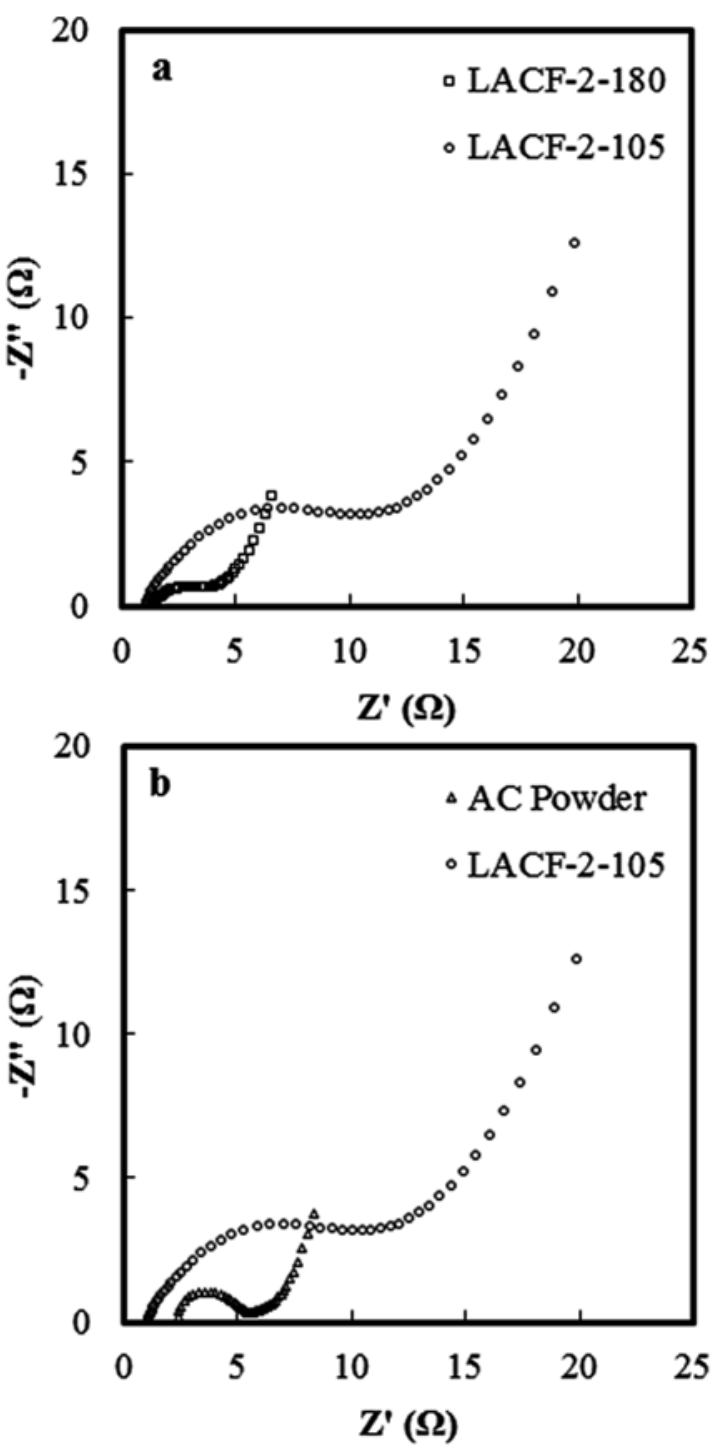

Figure 8: Nyquist plots with comparisons between (a) LACF-2-180and LACF-2-105-based EDLCs (with same intrinsic resistance and different polarization resistance); (b) AC powder and LACF-2-105based EDLCs (with different intrinsic resistance and polarization resistance).

indicates how much energy an EDLC stores, while power density is an indication for the speed of the electric charge release. These values were calculated from the specific capacitance, according to Equations (3) and (4), to compare the EDLC $_{\text {LACF-2-105 }}$ with that of EDLC $_{\text {ACpowder }}$ EDLC LACF-2-105 $_{\text {ans }}$ an energy density of $42 \mathrm{Wh} \mathrm{kg}^{-1}$ and a power density of $91 \mathrm{~kW} \mathrm{~kg}^{-1}$. EDLC $_{\text {ACpowder }}$ has an energy density of $20 \mathrm{Wh} \mathrm{kg}^{-1}$ and a power density of $102 \mathrm{~kW} \mathrm{~kg}^{-1}$. As mentioned earlier, the high performance of $\mathrm{EDLC}_{\mathrm{LACF}-2 \cdot 105}$ is attributable to the large surface area and proper pore size distribution.

Nyquist plots of EDLC $_{\text {LACF-2 }}$ and EDLC $_{\text {ACpowder }}$ are presented in Figure 8 in a frequency range from 100 $\mathrm{kHz}$ to $1 \mathrm{~Hz}$. Both profiles show one semicircle at the 

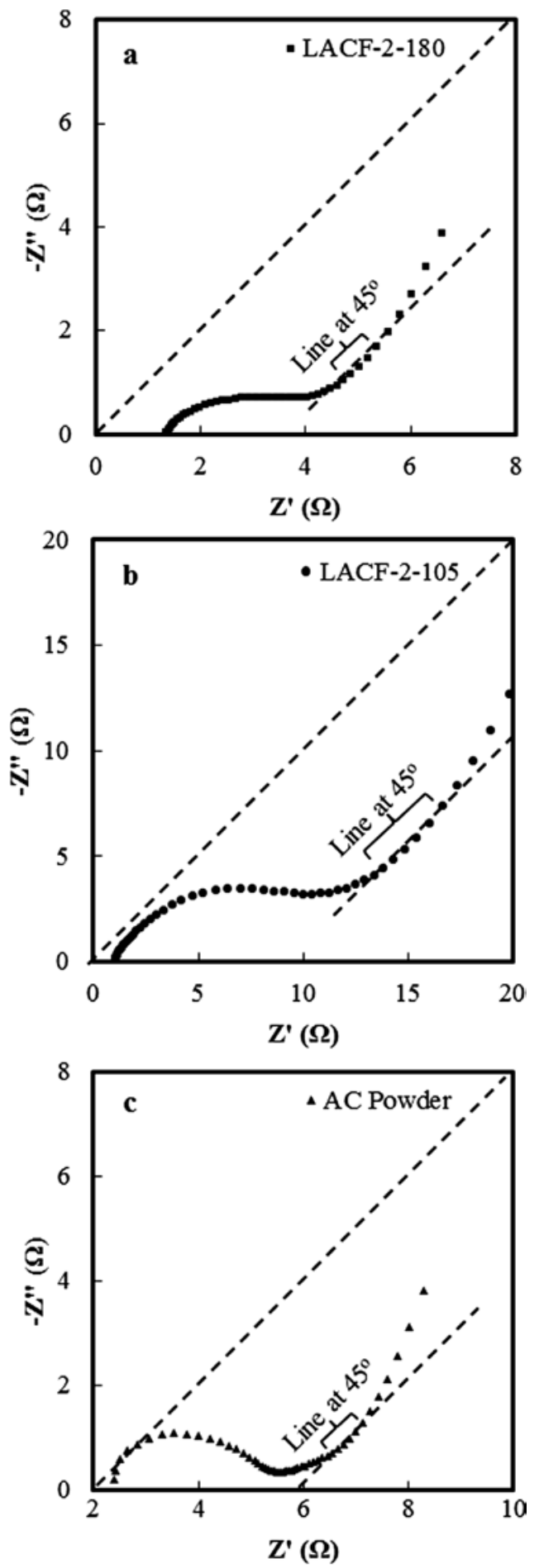

Figure 9: Diffusion resistance of (a) LACF-2-180, (b) LACF-2-105, and (c) AC powder represented in the Nyquist plots.

high-frequency region (low $\mathrm{Z}^{\prime}$ area) and slope line at the low-frequency region (high $Z^{\prime}$ area). Both LACF-2-105- and LACF-2-180-based EDLC have lower intrinsic resistance of $1.1 \Omega$ than that of AC powder (2.4 $\Omega$ ) at the intercept of $Z^{\prime}$ axis (Liu et al. 2008; Lu et al. 2012).
The profile of EDLC $_{\text {LACF-2-105 }}$ displays a relatively insufficient mobility of electrolyte ions compared to $\mathrm{EDFC}_{\mathrm{LACF}-2-180^{\circ}}$. A polarization resistance, as a measure of electrolyte mobility for adsorption and desorption rates of the electrolyte into/from the pores of carbonaceous electrode, can be obtained from the diameter of the semicircle at the high-frequency region (Liu et al. 2008). The polarization resistance of LACF-2-105-based EDLC was larger than that of LACF-2-180 and AC powder-based EDLC, thus, the adsorption and desorption rates of the electrolyte on LACF2-105 are slower than those on LACF-2-180 and AC powder. In addition, the line length of slope at the angle of $45^{\circ}$ in a low-frequency region means diffusion resistance in the pore (Figure 9) (Liu et al. 2008). The length in the profile of EDLC $_{\text {LACF-2-105 }}$ is also longer than that of EDLC $_{\text {LACF-2-180 }}$ and $\mathrm{EDLC}_{\mathrm{ACpowder}}$, indicating the higher diffusion resistance of EDLC $_{\text {LACF-2-105 }}$. The insufficient mobility of the electrolyte is probably caused by the smaller pore size distribution of LACF-2-105 (0.5-1.3 nm) compared with that of LACF-2-180 (1.3-3.0 nm) and AC powder (macropores).

\section{Conclusions}

Easily thermostabilized lignin-based electrospun fibers were successfully prepared from a mixed solution of HW-AAL and hexamine in a binary solvent system. This solution system contributed not only to reduce the thermostabilization time but also to develop more small pores on the ACFs surface. Accordingly, the resultant ACFs from the fibers have a larger surface area $\left(2185 \mathrm{~m}^{2} \mathrm{~g}^{-1}\right)$ and better developed micropores and smaller number of mesopores than other carbonaceous samples. This ACF (LACF-2-105)based EDLC had a satisfactory electrochemical performance, namely, a relatively high capacitance $\left(133.3 \mathrm{~F} \mathrm{~g}^{-1}\right.$ at a current density of $1 \mathrm{~A} \mathrm{~g}^{-1}$ ), an energy density of $42 \mathrm{Wh} \mathrm{kg}^{-1}$, and a power density of $91 \mathrm{~kW} \mathrm{~kg}^{-1}$. The good performance is probably due to the large surface area and highly developed pores in the range of $0.5-1.3 \mathrm{~nm}$, although this pore size distribution also resulted in high polarization and diffusion resistance.

The EDLCs from the isolated lignins as presented here offer a very attractive prospect for energy storage devices, though further research is needed in this field.

Acknowledgments: This work was supported by a grant from the Ministry of Agriculture, Forestry and Fisheries of Japan, "Development of Technologies for Biofuel Production Systems in Rural Areas (2012-2015)”. We would also like to thank Prof. Aorigele (South China University of Technology, China) for his valuable advice to our work. 


\section{References}

Babel, K., Jurewicz, K. (2008) KOH activated lignin based nanostructured carbon exhibiting high hydrogen electrosorption. Carbon 46:1948-1956.

Bose, S., Kuila, T., Mishra, A.K., Rajasekar, R., Kim, N.H., Lee, J.H. (2012) Carbon-based nanostructured materials and their composites as supercapacitor electrodes. J. Mater. Chem. 22:767-784.

Bozell, J.J., Petersen, G.R. (2010) Technology development for the production of biobased products from biorefinery carbohydrates-the US Department of Energy's “Top 10” revisited. Green Chem. 12:539-554.

Burke, A. (2007) R\&D considerations for the performance and application of electrochemical capacitors. Electrochim. Acta 53:1083-1091.

Calvo-Flores, F.G., Dobado, J.A. (2010) Lignin as renewable raw material. ChemSusChem 3:1227-35.

Chmiola, J., Yushin, G., Gogotsi, Y., Portet, C., Simon, P., Taberna, P.L. (2006) Anomalous increase in carbon capacitance at pore sizes less than 1 nanometer. Science 313:1760-1763.

El-Kady, M.F., Strong, V., Dubin, S., Kaner, R.B. (2012) Laser scribing of high-performance and flexible graphene-based electrochemical capacitors. Science 335:1326-1330.

Feng, Y., Aorigele. (2009) Preparation of lignin-based nanofibers by electrospinning. Paper Sci. Technol. 28:29-32.

Fitzer, E., Müller, D.J. (1975) The influence of oxygen on the chemical reactions during stabilization of pan as carbon fiber precursor. Carbon 13:63-69.

Im, J.S., Park, S.-J., Lee, Y.-S. (2007) Preparation and characteristics of electrospun activated carbon materials having meso- and macropores. J. Colloid Interface Sci. 314:32-37.

Imaizumi, S., Matsumoto, H., Suzuki, K., Minagawa, M., Kimura, M., Tanioka, A. (2009) Phenolic resin-based carbon thin fibers prepared by electrospinning: additive effects of poly(vinyl butyral) and electrolytes. Polym. J. 41:1124-1128.

Inagaki, M. (2009) Pores in carbon materials-importance of their control. New Carbon Mater. 24:193-232.

Inagaki, M., Konno, H., Tanaike, O. (2010) Carbon materials for electrochemical capacitors. J. Power Sources 195:7880-7903.

Kadla, J.F., Kubo, S., Venditti, R.A., Gilbert, R.D., Compere, A.L., Griffith, W. (2002) Lignin-based carbon fibers for composite fiber applications. Carbon 40:2913-2920.

Kim, C., Yang, K.S. (2003) Electrochemical properties of carbon nanofiber web as an electrode for supercapacitor prepared by electrospinning. Appl. Phys. Lett. 83:1216-1218.

Kim, T., Jung, G., Yoo, S., Suh, K.S., Ruoff, R.S. (2013) Activated graphene-based carbons as supercapacitor electrodes with macro- and mesopores. ACS Nano 7:6899-6905.

Kubo, S., Kadla, J.F. (2005) Lignin-based carbon fibers: effect of synthetic polymer blending on fiber properties. J. Polym. Environ. 13:97-105.

Kubo, S., Uraki, Y., Sano, Y. (1998) Preparation of carbon fibers from softwood lignin by atmospheric acetic acid pulping. Carbon 36:1119-1124.
Lai, C., Zhou, Z., Zhang, L., Wang, X., Zhou, Q., Zhao, Y., Wang, Y., Wu, X.-F., Zhu, Z., Fong, H. (2014) Free-standing and mechanically flexible mats consisting of electrospun carbon nanofibers made from a natural product of alkali lignin as binder-free electrodes for high-performance supercapacitors. J. Power Sources 247:134-141.

Liu, C.L., Dong, W.S., Cao, G.P., Song, J.R., Liu, L., Yang, Y.S. (2007) Influence of $\mathrm{KOH}$ followed by oxidation pretreatment on the electrochemical performance of phenolic based activated carbon fibers. J. Electroanal. Chem. 611:225-231.

Liu, C.L., Dong, W.S., Cao, G.P., Song, J.R., Liu, L., Yang, Y.S. (2008) Capacitance limits of activated carbon fiber electrodes in aqueous electrolyte. J. Electrochem. Soc. 155:F1-F7.

Liu, S., Song, Y., Ma, C., Shi, J.-L., Guo, Q.-G., Liu, L. (2012) The electrochemical performance of porous carbon nanofibers produced by electrospinning. Carbon 50:3963.

Lu, H., Dai, W., Zheng, M., Li, N., Ji, G., Cao, J. (2012) Electrochemical capacitive behaviors of ordered mesoporous carbons with controllable pore sizes. J. Power Sources 209:243-250.

Martin, C., Ronda, J.C., Cadiz, V. (2006) Development of novel flame-retardant thermosets based on boron-modified phenol-formaldehyde resins. J. Polym. Sci. Part a-Polym. Chem. 44:3503-3512.

Neimark, A.V., Lin, Y., Ravikovitch, P.I., Thommes, M. (2009) Quenched solid density functional theory and pore size analysis of micro-mesoporous carbons. Carbon 47:1617-1628.

Qu, D., Shi, H. (1998) Studies of activated carbons used in doublelayer capacitors. J. Power Sources 74:99-107.

Rosas, J.M., Bedia, J., Rodriguez-Mirasol, J., Cordero, T. (2009) HEMP-derived activated carbon fibers by chemical activation with phosphoric acid. Fuel 88:19-26.

Ruiz-Rosas, R., Valero-Romero, M.J., Salinas-Torres, D., RodriguezMirasol, J., Cordero, T., Morallon, E., Cazorla-Amoros, D. (2014) Electrochemical performance of hierarchical porous carbon materials obtained from the infiltration of lignin into zeolite templates. ChemSusChem 7:1458-1467.

Simon, P., Gogotsi, Y. (2008) Materials for electrochemical capacitors. Nat. Mater. 7:845-854.

Suhas, Carrott, P.J.M., Ribeiro Carrott, M.M.L. (2007) Lignin - from natural adsorbent to activated carbon: a review. Bioresour. Technol. 98:2301-2312.

Uraki, Y., Kubo, S., Nigo, N., Sano, Y., Sasaya, T. (1995) Preparation of carbon fibers from Organosolv lignin obtained by aqueous acetic acid pulping. Holzforschung 49:343-350.

Uraki, Y., Nakatani, A., Kubo, S., Sano, Y. (2001) Preparation of activated carbon fibers with large specific surface area from softwood acetic acid lignin. J. Wood Sci. 47:465-469.

Wang, G., Zhang, L., Zhang, J. (2012) A review of electrode materials for electrochemical supercapacitors. Chem. Soc. Rev. 41:797-828.

Xu, B., Wu, F., Chen, S., Zhang, C.Z., Cao, G.P., Yang, Y.S. (2007) Activated carbon fiber cloths as electrodes for high performance electric double layer capacitors. Electrochim. Acta 52:4595-4598.

Zhang, L.L., Zhao, X.S. (2009) Carbon-based materials as supercapacitor electrodes. Chem. Soc. Rev. 38:2520-2531. 